\title{
Reversing Flow in Charged Membranes
}

\section{The process of osmosis is predicted-under certain conditions-to act in} the opposite direction within charged membranes.

\author{
By Michael Schirber
}

$\prod$ he classical example of osmosis is water moving across a membrane to balance the salt concentration on the membrane's two sides. Typically, the process reduces concentration differences in fluids. But new computations by Alain Boldini and Maurizio Porfiri of New York University suggest that this osmotic flow could change direction across a charged membrane, leading to an increase in concentration differences [1]. The researchers expect the effect to be observable in microfluidic systems, where fluid volumes are small and highly controllable.

Charged membranes are common in biological cells and electrochemical devices. To model such a system, Boldini and Porfiri imagined a porous material with fixed charges. They applied a voltage across the membrane's surface and computed how a solvent with free-moving ions would behave inside the material. This type of modeling has been done before, but the researchers included the elastic deformation of the membrane caused by the pile-up of ions. The results showed that-if the

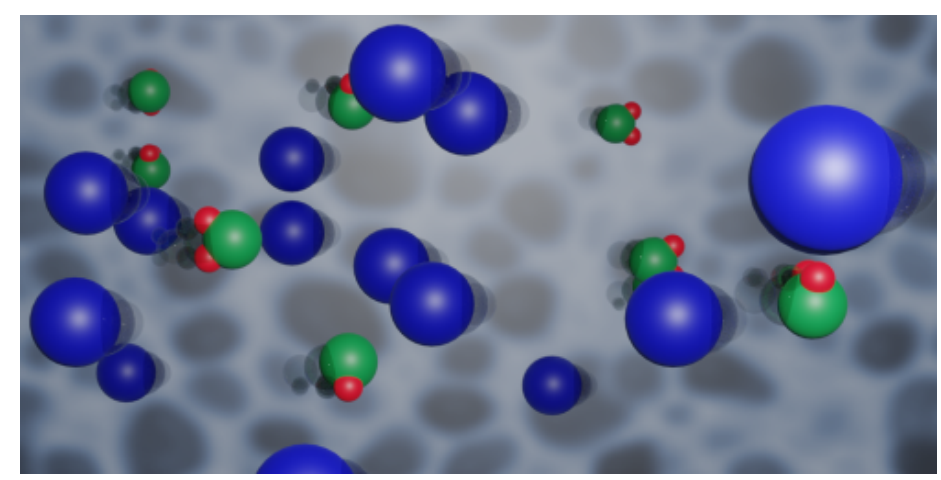

Credit: A. Boldini, A. Sawulska, M. Porfiri/New York University ions are large enough in size-they can inflate the membrane, creating a pressure that causes the solvent to flow in the direction opposite to the one it would in osmosis.

The researchers call their finding "inversion of solvent migration" to distinguish it from "reverse osmosis," which occurs when external pressure is applied to one side of a membrane. They say that the reason that this inverted migration has, so far, been unobserved is that it occurs at the submicrometer scale, below the resolution of concentration-measuring techniques. However, the researchers believe that their predicted flow reversal could be demonstrated in microfluidic devices, where it could be used to concentrate compounds for nanofabrication.

Michael Schirber is a Corresponding Editor for Physics based in Lyon, France.

\section{REFERENCES}

1. A. Boldini and M. Porfiri, "Inversion of solvent migration in charged membranes," Phys. Rev. Lett. 127, 156001 (2021). 